\title{
A casa está na mão de quem? Hierarquia e relações de poder no interior de Unidades de Internação destinadas a jovens infratores
}

\author{
Maurício Bacic Olic
}

\begin{abstract}
resumo $\mathrm{O}$ presente artigo tem como objetivo analisar como ocorre o embate de forças no interior das diferentes Unidades de Internação do Centro de Atendimento Social ao Adolescente (antiga FEBEM). Por meio de observaçóes empíricas do dia a dia dentro de Unidades - realizadas como professor da escola formal entre os anos de 2004-06 dentro do Complexo Raposo Tavares localizado na cidade de São Paulo -, buscar-se-á avaliar a dinâmica e os mecanismos de poder que permeiam a rotina dos adolescentes e dos profissionais que ali trabalham para o cumprimento da medida socioeducativa.
\end{abstract}

palavras-chave Unidade de Internação (CASA). Hierarquia. Sistema socioeducativo.

\section{Introduçáo}

Um dos principais objetivos do presente texto será avaliar a dinâmica de como se estruturam os embates e as configuraçóes de poder no interior das Unidades de Internação pertencentes à Fundação Estadual do Bem Estar do Menor - FEBEM-SP -, atual Centro de Atendimento Social ao Adolescente (CASA), e como que esta relação se reflete na criação de uma espécie de escala hierárquica entre diferentes Unidades, dadas a partir de um sistema classificatório pautado no perfil que cada casa possui.

Segundo o artigo 122 do Estatuto da Criança e do Adolescente (ECA), a aplicação da me- dida socioeducativa de internação deve ocorrer caso o ato de contravenção for cometido mediante grave ameaça ou violência à pessoa, por reiteraçóes no cometimento de outras infrações graves e por descumprimento da medida anteriormente imposta. O período máximo de internação é de três anos, e os adolescentes que cumprem essa medida são submetidos a avaliação judicial a cada seis meses de permanência na Unidade.

Nesta perspectiva, ao buscar desvendar as micropolíticas existentes por detrás da medida socioeducativa de privação de liberdade, o artigo irá mostrar como as Unidades - e consequentemente os adolescentes que a ocupam - constroem para si um perfil que permite observar a existência de singularidades e diferenciações que vão além da condição genérica do menor infrator privado de liberdade, ou do adolescente cumprindo a medida socioeducativa. Assim, será investigado como cada Unidade constrói para si um determinado padrão que passa a orientar a ação dos adolescentes no interior de cada casa, que, além de determinar o perfil de cada Unidade, remete, em muitos casos (como será visto no decorrer do texto), para a importância e a valorização da violência em prol da medida socioeducativa. Neste sentido, para compreender as relaçóes no interior das Unidades - por meio da construção de formas hierárquicas - tornar-se-á necessário compreender a violência: 
io8 | Maurício Bacic Olic

[...] como uma certa modalidade disciplinada de auto-realização, de produção de si, de relacionamento. É uma modalidade de organizar a experiência da sociabilidade ainda que acabe dissipando as condiçóes mesmas da experiência da sociabilidade [...] a violência não é negatividade, não é vazio, não é o oposto da cultura, ainda que seja a barbárie. É a barbárie como uma certa configuraçáo cultural, enquanto uma certa modulação da cultura, um certo arranjo de linguagens que ordenam as posturas individuais, físicas, mentais e as disposiçóes subjetivas (Soares, 2006, p. 126).

Com isso, a violência será o eixo norteador da descrição dos embates de poder no interior das casas - enquanto uma manifestação "boa para se pensar" os processos de socialização nas Unidades -, pois, sendo a violência "uma formação cultural, deveríamos poder descrevê-la e identificar algumas de suas regras, revelando sua gramática” (Soares, 2006, p. 126).

Do ponto de vista metodológico, devido às dimensões da instituição e à existência de diferentes complexos ${ }^{1}$, a opção adotada foi a de fazer um recorte no sentido da construção de uma totalidade para observação, baseada em um espaço mais bem delimitado. Deste modo, valendo-se da posição do autor enquanto professor da escola formal que funciona no interior do Complexo Raposo Tavares (entre os anos de 2004-06) - localizado na cidade de São Paulo, próximo à divisa com os municípios de Osasco, Cotia e Taboão da Serra -, a construção da totalidade de análise terá como foco as cinco Unidades de Internação $(22,27,28,37,38)$ que funcionam em seu espaço ${ }^{2}$.

No que tange à atuação do professor no interior das Unidades de Internação, cabe ressaltar que ele não é propriamente um funcionário da Fundação, como acontece com as equipes pedagógica, técnica e de segurança ${ }^{3}$. O professor, embora esteja cotidianamente no interior das Unidades, é um profissional ligado à Secretaria Estadual da Educação, sendo que, no caso do Complexo Raposo Tavares, os docentes (assim como os adolescentes internados) estão vinculados à E. E. Professor Oswaldo Walder, localizada em um bairro vizinho ao Complexo.

Neste sentido, a construção das informações presentes no decorrer do texto é fruto da experiência vivida empiricamente no interior das diferentes Unidades existentes no Complexo, experiência esta em que o professor ocupa uma posição que pode ser considerada "à deriva” entre os funcionários (já que é um profissional que, assim como eles, está ali para a aplicação da medida socioeducativa) e os adolescentes (pois, além do professor não ser identificado pelos internos como sendo um funcionário da Fundação, a prática da docência permite uma maior possibilidade de construção de vínculos afetivos ${ }^{4}$ com os adolescentes).

Logo, a posição "à deriva” pode fazer com que o professor (caso tenha esse objetivo) experimente novas formas de trabalho de campo - diferente dos processos de observação, conversão (assumir o ponto de vista do outro), ou ainda de transformação (tornar-se nativo) (Goldman, 2006) -, de modo que a escrita etnográfica resulte da prática do que Gilles Deleuze e Félix Guattari denominaram de devir, assim experimentado por Marcio Goldman no contexto etnográfico:

[...] é o movimento pelo qual um sujeito sai de sua própria condição por meio de uma relação de afetos que consegue estabelecer com uma condição outra. Estes afetos não têm absolutamente o sentido de emoçóes ou sentimentos, mas simplesmente daquilo que afeta, que atinge, que modifica [...]. O devir, assim, é o que nos arranca não apenas de nós mesmos, mas de toda identidade substancial possível (Goldman, 2006, p. 31). 
Portanto, o caminho a ser traçado almeja, ao encarar a violência como forma cultural, compreender como se organizam as configuraçóes de poder que subjazem ao cumprimento da medida socioeducativa de privação de liberdade. Para isso, buscar-se-á, por meio do devir, construir novos territórios existenciais (Deleuze; Guattari, 1997) que atravessem as forças molares em jogo (o Estado como perpetrador de uma "vingança social", e o Crime enquanto forma de reiteração de uma "cultura carcerária").

\section{Os ciclos de violência: mudam-se os jogadores, mas o jogo é o mesmo}

Um primeiro fator a se destacar - dentro do espaço de tempo que o presente artigo se propôs a analisar - é que o ano de 2004 foi marcado pela inauguração das chamadas "Unidades gêmeas" (37 e 38) dentro do Complexo Raposo Tavares, consideradas então como uma estrutura modelo ideal para abrigar 75 internos, mas que desde o início passaram a abrigar por volta de 150 .

Estas Unidades abrigavam internos com o perfil de "primários graves"; contudo, em consequência da rebelião seguida por uma fuga em massa que veio a ocorrer no Complexo de Franco da Rocha no primeiro semestre de 2004, quase todos os internos destas duas Unidades passaram a ser transferidos para outras Unidades espalhadas no estado, no intuito de que os adolescentes recapturados de Franco da Rocha fossem alocados em um local considerado de maior segurança. Sobre a "fama" dos adolescentes internados em Franco da Rocha, o funcionário Laércio Narciso no livro "Cadeia de chocolate" coloca:

[...] os internos de Franco da Rocha tinham uma fama de grande violência e crueldade. Assassinatos, decapitaçóes [...] eles vinham de ter destruído a unidade da Imigrantes, depois foram jogados para Pinheiros, jogados para Santo André, jogados para o Centro de Observação de Criminologia, no Carandiru. Aí o que aconteceu com esses moleques? Eles destruíram uma, destruíram outra, e tivemos que sair de Pinheiros e depois focar onde?... Em Franco da Rocha (Farias; Narciso, 2006, p. 71-72).

Esta situação fez com que o Complexo Raposo Tavares passasse a abrigar também internos "reincidentes graves" (UI-38) e "reincidentes graves gravíssimos" (UI-37), isto é, adolescentes que cometeram delitos considerados graves (homicídio, estupro, tráfico de drogas, latrocínio, extorsão por meio de sequestro) e que já têm mais de uma passagem pela instituição. Os "reincidentes graves gravíssimos" são aqueles que, além de terem cometido crimes graves, também possuem um histórico violento dentro da Fundação (lideraram rebeliōes e ataques contra funcionários e outros adolescentes). Geralmente, neste tipo de Unidade existe um número grande de internos com mais de dezoito anos, mas que por terem cometido o delito quando ainda eram menores de idade acabam sendo enviados para a Fundação.

Em agosto de 2004, a Fundação também passou por uma mudança institucional, visto que deixou de estar vinculada à pasta da Secretaria da Educação (onde estava desde 2002) e passou para a Secretaria de Justiça e Cidadania (Ramos, 2004). No entanto, o impacto desta mudança só veio a ser realmente sentida em janeiro de 2005, período este em que o então presidente da Fundação, Alexandre Moraes, sob um discurso de reestruturação da instituição visando ao melhor cumprimento da medida socioeducativa, ordenou a demissão em massa dos antigos funcionários que trabalhavam no pátio dos grandes Complexos - tanto da área pedagógica como da de segurança. 
Em seus postos foram colocados estudantes universitários, recém-formados e professores aposentados sem nenhum tipo de experiência na fundação, que passaram a exercer tanto a função da área pedagógica como a de segurança. Isto porque, na nova política da Fundação, a função do agente de segurança - estigmatizados em sua totalidade como torturadores - fora abolida em prol da figura do educador social.

Isto fez com que a situação, que já não era boa, apenas piorasse. Na passagem de 2004 para 2005 a FEBEM passou a estar nas manchetes dos jornais em decorrência da explosão no número de rebelióes e de fugas dos adolescentes, em especial nos grandes complexos, tais como os do Tatuapé, Raposo Tavares, Vila Maria e Franco da Rocha. Durante o ano de 2005 foram registradas oficialmente 34 rebeliōes e 1294 fugas de adolescentes da instituição (Penteado, 2006). Sobre a relação entre mudança na gestão administrativa e desestruturação das relaçôes no interior de instituiçóes totais (Goffman, 1974), Sérgio Adorno e Fernando Salla apontam:

[...] que a expectativa de mudanças na gestão administrativa das prisóes é sempre percebida com inquietaçấo. Em um ambiente em que as relaçóes sociais são arranjos precários, carentes de reciprocidade, marcados por relaçôes desiguais e hierárquicas, sujeitas a rupturas inesperadas, quaisquer mudanças nos postos administrativos acentuam esses sentimentos. As reaçóes estão sempre de prontidão (Adorno; Salla, 2007, p. 24).

Neste período, no interior das Unidades, na sombra dos holofotes da mídia, a situação de descontrole institucional atingiu um patamar elevado. Isto porque, dentro da perspectiva da Fundação, marcada pela privação da liberdade, os internos se viram livres de uma espécie de "contrapoder" exercido até então pelos funcionários de segurança (que em muitos casos, inclusive, são acusados de cometer atos violentos para impor a rotina institucional e limitar o poder de ação dos internos). O parágrafo abaixo ilustra a situação vivida pelos funcionários no interior dos Complexos no período:

No Tatuapé, após ser ameaçado de morte por um interno, Laércio fez um boletim de ocorrência e se licenciou da FEBEM, no dia 21 de janeiro. Naquele complexo, várias alas estavam na mão literalmente dos adolescentes, com os funcionários recém-contratados (alguns trabalhando sem contrato de trabalho ou cartão de ponto) sendo ameaçados para que trouxessem drogas e outros itens, para os internos. Muitos estavam desistindo assim que se deparavam com as condiçóes reais de trabalho (Farias; Narciso, 2006, p. 15).

Com isso, os adolescentes passaram a exercer poderes plenos no interior das casas, em muitos casos, inclusive, se sobrepondo ao poder dos diretores, de modo a produzirem uma nova rotina que náo a institucional. Ou seja, muitas Unidades passaram a estar na mão dos adolescentes. No caso do Complexo Raposo Tavares pode ser observado que, excetuando-se a Unidade 22, todas as outras casas passaram a estar cada vez mais sob controle dos adolescentes, que, por sua vez, passaram a estipular quais funcionários poderiam ou não adentrar na Unidade 5 .

Esta situação fez com que inclusive as atividades pedagógicas - identificadas por parte dos internos como açóes institucionais coercitivas (já que, segundo o ECA, os adolescentes são obrigados a estudar e a frequentar os cursos profissionalizantes) - passaram a perder espaço ou simplesmente deixaram de existir. Outro fator que levou a uma diminuição das atividades pedagógicas foi a falta de condiçóes estruturais mínimas para que os profissionais desta área exercessem seu ofício. A título de exemplo, 
pode-se citar a estrutura da escola formal, em que a falta de carteiras, lousas, lápis, cadernos e até mesmo de salas de aula (equipamentos estes muitas vezes destruídos durante as rebelióes), fez com que o trabalho dos professores fosse prejudicado. Soma-se ainda a falta de segurança para os educadores exercerem seu ofício, de modo que, em muitos casos, estes profissionais passam a se recusar a entrar nas Unidades visando manter sua integridade física e psicológica ${ }^{6}$.

É nestes períodos de maiores turbulências que os diferentes profissionais que trabalham no interior das Unidades passam a ser alvos do chamado psicão, categoria nativa que designa a ação intimidadora dos adolescentes frente aos diferentes profissionais que atuam na instituição. $\mathrm{O}$ nome dado a esta ação se justifica pela estratégia utilizada pelos adolescentes de entrar na mente (no psicológico), apropriando-se das fraquezas e medos, como forma de assujeitamento e coação de sua vítima. $\mathrm{O}$ adolescente, ao exercer o psicão, busca, por meio da intimidação, que funcionários de diferentes áreas lhe cumpram favores e tragam mercadorias existentes apenas do lado de fora, em especial drogas ilícitas; em troca, geralmente, o interno oferece uma suposta segurança nos momentos em que acontecem as rebelióes.

No entanto, é importante ressaltar que os embates de poder não se resumem apenas à relação entre funcionários e adolescentes, mas ocorrem também entre internos e internos. Isto porque, embora o discurso dos adolescentes acene para uma possível situação de igualdade e respeito entre os internos, a constituição de redes de lideranças acaba, em muitos casos, reproduzindo e aprofundando o ciclo de violência no interior das Unidades contra adolescentes da chamada população (aqueles que não ocupam nenhum posto hierárquico na casa). Logo, é ingênuo pensar que a tomada do poder decisório por parte dos adolescentes no interior das Unidades se configure como:
O embriāo da revolução social e da construção de uma nova sociedade baseada na justiça, na igualdade e na democracia [...] Suas lideranças não têm pudor punitivo; não hesitam em matar e aplicar justiça sem direito à defesa (Adorno; Salla, 2007, p. 24).

Esta situação de violência entre os adolescentes ocorre de modo mais acentuado quando uma Unidade passa a estar sujeita ao comando de um grupo de internos, que busca impor uma estrutura carcerária no interior das casas. O funcionário Paulo Sérgio Farias assim descreveu os anseios das lideranças após uma rebelião em Franco da Rocha:

O desejo deles era viver dentro de um esquema de cadeião mesmo, sem regras. Não há nenhum interesse coletivo, nada dirigido a todos internos, nenhuma reivindicação de melhorias ou de melhores tratos. Os líderes fazem tudo por interesse próprio, por vantagens imediatas, mas colocam todos para trabalhar por eles durante uma rebelião (Farias; Narciso, 2006, p. 73).

Para os profissionais que atuam nas Unidades, estas lideranças são consideradas "negativas", pois exercem um poder que não contribui para que a casa ande no sentido do cumprimento da medida socioeducativa. Geralmente, visam aprofundar ainda mais a "estrutura carcerária” no interior das Unidades, no intuito de concentrar um maior poder e status nas mãos da liderança. Por sua vez, os adolescentes da chamada população acabam por se sujeitar ao domínio destas lideranças, em virtude do medo que "está associado com a permanente ameaça de violência física. Venha de onde e de quem vier" (Adorno; Salla, 2007, p. 16).

Portanto, para os adolescentes que vivem nestas Unidades - que buscam se estruturar por meio de uma cultura carcerária -, o campo de possibilidades de uma reinvenção de si 
(Soares, 2006) por meio do cumprimento da medida socioeducativa se vê reduzido frente ao embate de forças que passam a ser travadas entre o Crime e o Estado, em que a violência, seja de que lado vier, "constitui o código normativo de comportamento" (Adorno; Salla, 2007, p. 16). Cleonder Evangelista assim narrou a expectativa que o consumia antes de ser enviado para uma dessas Unidades:

Já conhecíamos nosso destino, Franco da Rocha nunca foi bem vista e os internos eram considerados de Alta Periculosidade, sendo autores de Crimes Graves e Gravíssimos. Também conhecíamos a rigidez desse complexo. Os funcionários batem demais e os internos revidam com muita agressividade. Fui tomado pela sensação de medo (Evangelista, 2004, p. 157).

Em virtude destas diferentes situações que passaram a figurar no cotidiano das casas, o primeiro semestre de 2005 ficou marcado pela constituição de um processo formado por "pequenos ciclos de violência" no interior das Unidades. Estes ciclos são constituídos, em um primeiro momento, por movimentos em que os adolescentes, após atingirem uma espécie de limite nas conquistas pleiteadas junto à direção, tal como aumento no $j u m b o^{7}$, aquisição de aparelhos eletrônicos, aumento no tempo das visitas e visitas íntimas, passam a atingir um impasse junto à direção, visto que os pedidos alcançam o limite de aceitação por parte do diretor. Em relatório referente à rebeliāo ocorrida na UI-41 de Franco da Rocha em 22 de novembro de 2004, o funcionário Paulo Sérgio Farias descreveu desta forma o processo que envolve a negociação entre os internos e a direção:

Entrando no pátio aproximei-me dos internos [...] Ouvimos dos adolescentes ameaças, caso não fosse cumprido o acordo firmado com o
Diretor de Divisão [...] de que seria liberado para os internos, entre outras coisas, visita íntima; comida da rua sem ser revistada; pátio total; três horas de visita com familiares aos sábados. É importante salientar que algumas concessóes afrontam o Regimento Interno das Unidades da FEBEM [...] explicamos para os jovens que seria inviável o atendimento das reivindicaçóes referentes aos dois primeiros itens, e que os demais já faziam parte da rotina da Unidade. Os internos elegeram uma comissão para conversar com o diretor da Unidade [...] Após o retorno da comissão, solicitamos aos jovens que entrassem em formação para subirem aos alojamentos. Mais da metade dos alunos já se encontrava formada, quando o interno [...] gritou: 'Boa! Boa! Vamos virar esta porra! Neste instante, os internos começaram a se apoderar de cadeiras e outros objetos, para atingir os funcionários [...] (Farias; Narciso, 2006, p. 105).

A situação descrita acima mostra o processo pelo qual as negociaçóes políticas se encerram e o clima de guerra se instaura. Isto porque, não tendo nada mais a reivindicar - já que a situação de negociação alcançou o limite - os adolescentes passam, portanto, a destruir a Unidade como sinal de descontentamento, e/ ou como forma de programar fugas da instituição, pois esta se torna agora a única conquista a ser pleiteada por eles; a busca por sua liberdade. É nestes momentos que os internos viram a casa:

Virar a casa é ter a unidade nas mãos dos internos, ou seja, fora do controle da autoridade constituída, os funcionários. Quando a casa vira, os internos fazem a lei (Farias; Narciso, 2006, p. 105).

$\mathrm{Na}$ maior parte dos casos estas açóes culminam em rebeliôes com reféns e na consequente invasão do choquinho ${ }^{8}$ ou, em casos mais gra- 
ves, a Tropa de Choque da Polícia Militar é chamada para "restabelecer a ordem". Como pude atestar nas conversas com os internos - dentro da lógica da violência como código normativo de comportamento -, a Tropa de Choque da PM é respeitada pelos adolescentes em virtude do seu poder de ação - como dizem: "Com o Choque não tem ideia, não dá para bater de fren$t e$ ". Este respeito advém do temor de possíveis represálias frente a uma força que se sobrepóe à dos internos, como mostra Paulo Sérgio Farias:

O maior temor dos internos é o confronto com essa tropa especial da PM, porque ela entra jogando gás lacrimogêneo e disparando bombas de efeito moral e balas de borracha, e porque os internos são despidos e a revista que é feita neles é total (Farias; Narciso, 2006, p. 77).

O mesmo não acontece com o choquinho em especial nas Unidades com uma população de "reincidentes" -; para muitos adolescentes, este grupo fica em choque (com medo) ao entrar em confronto com os internos, sendo que, diversas vezes, ao adentrar as Unidades para conter tumultos, são expelidos violentamente pelos adolescentes. É nestas ocasióes que a Tropa de Choque é acionada.

Após o término dos tumultos, os adolescentes imediatamente recebem uma sanção com um período de tranca - método de punição em que os adolescentes ficam confinados em seus quartos praticamente durante todo o dia, não tendo mais livre acesso ao pátio. Esta ação possibilita que os funcionários (muitas vezes com o apoio do choquinho) possam restabelecer o controle institucional no interior da Unidade.

Todavia, a retomada da Unidade por parte dos funcionários nem sempre é pacífica; em alguns casos, os adolescentes - que antes, ao virarem a casa, ocupavam a posição de algoz, maltratando e impedindo muitos funcionários de trabalhar no pátio - passam agora à posi- ção de vítimas de constrangimentos impelidos pelos "novos donos da casa"; os funcionários. Estes que anteriormente, quando a Unidade estava sob poder dos internos, eram as vítimas das violências físicas e psicológicas que, muitas vezes, passam agora a praticar.

O ciclo se completa com o fim da tranca, sendo que em alguns casos - como, por exemplo, na UI-27 em 2004 - esta punição encerrase somente após a intervenção judicial externa e o afastamento da direção da Unidade e de parte do grupo de funcionários, sob a alegação de maus tratos aos adolescentes. Após a liberação da tranca, os adolescentes retomam o processo de conquista da casa. Movimento este marcado pela negociação entre a liderança dos internos e a direção, em que, pelo lado da direção, almeja-se que a casa continue andando, isto é, que as atividades socioeducativas aconteçam cotidianamente. Por outro lado, para os internos, que durante o período em que vigorou a tranca perderam todos "direitos" anteriormente conquistados, as negociações são uma estratégia de reconquistar o espaço perdido. Um novo ciclo se inicia. Embora este processo sempre tenha ocorrido em Unidades consideradas problemáticas da Fundação (geralmente aquelas que atendem a uma população reincidente), em 2005 este ciclo de violência se tornou mais constante.

Pressionado pela mídia e pela opinião pública, o governo do Estado passou então a adotar medidas para que a situação na Fundação voltasse à "normalidade". As principais ações consistiram, em primeiro lugar, na intensificação de transferências de lideranças envolvidas em rebelióes para os Centros de Detenção Provisória (CDPs). Outra medida foi a transferência de grande parte dos adolescentes acima de dezoito anos para o desativado presídio de Tupi Paulista, onde passaram a ser tratados sob o Regime Disciplinar Diferenciado não mais por funcionários da Fundação, mas por agentes 
vinculados à Secretaria de Administração Penitenciária (SAP).

A criação desta Unidade provisória em Tupi passou a exercer uma "eficácia simbólica" importante na retomada da disciplina no interior das casas. Já que ela passou a ser utilizada como uma forma de intimidação para os adolescentes que exibiam um "mau comportamento" (não aceitavam a rotina institucional), estes passaram a ser ameaçados de que, caso não mudassem seu comportamento, seriam transferidos para Tupi, que além de estar localizada em um local distante da capital (dificultando a visita dos familiares), também tinha fama de ser uma casa que estava no veneno:

Unidade veneno quer dizer um lugar duro, severo, violento e rígido como na época da ditadura militar [...] Em unidades como esta, a pancada é uma ferramenta de trabalho, usada e abusada constantemente (Evangelista, 2004, p. 118).

Enfim, Tupi Paulista era um local no imaginário dos internos onde ninguém queria ir parar, onde a exceção tornara-se regra. Nestes ambientes, o caminho do cumprimento da medida socioeducativa, por meio de açóes pedagógicas, é preterido por açóes que privilegiem a contenção do adolescente.

Uma outra medida importante no período foi a crescente influência da administração penitenciária na Fundação ${ }^{10}$. A partir do segundo semestre de 2005, membros da SAP passaram a assumir as direçôes de determinadas Unidades; além disso, a presidência da Fundação passou a ser exercida por Berenice Gianella, que atuava na área do sistema penitenciário. Soma-se o fato ainda de que, nos grandes Complexos, membros do Grupo de Intervenção Rápida (GIR) - grupo especializado da SAP na "contenção de conflitos" no interior dos presídios - passaram a se fixar para atuar em caso de rebelióes, tentativas de fuga e, em alguns casos, na negociação direta com os internos ${ }^{11}$.
A situação de uma maior aproximação com a estrutura penitenciária, por sua vez, veio de encontro ao processo que já estava em andamento no interior de determinadas Unidades (em especial aquelas que abrigavam os adolescentes com um "perfil reincidente"), de estruturação de normas, costumes e hábitos construídos pelo Primeiro Comando da Capital (PCC) em presídios. Já que, frente à crescente desorganização do Estado e como forma de conter a crescente situação de desordem nas Unidades, os internos passaram a buscar formas próprias de organização para que a casa voltasse a andar.

Neste sentido, pode-se dizer que o PCC se estruturou no interior das Unidades como uma espécie de Estado dentro do Estado, na medida em que passa a se afirmar como defensor do território carcerário e governante de sua população. Por meio do apelo à condição genérica do detento como criminoso encarcerado (Adorno; Salla, 2007, p. 14) e do anseio coletivo expresso pelo lema - Paz, Justiça e Liberdade -, o "Partido" apresenta-se como uma força transcendente que disciplina e organiza as populações que vivem em seus territórios. A influência do PCC no Complexo Raposo Tavares pode ser verificada, por exemplo, na onda de ataques e rebeliōes atribuídas pelas autoridades ao PCC, em que, com exceção da UI-22, todas outras Unidades se amotinaram no mesmo instante após - como os internos mais tarde viriam a me dizer - uma "ordem vinda de cima", passada por meio de familiares durante a visita e via telefone celular.

Portanto, inspirados pela estrutura do "crime organizado" --em especial os aspectos referentes à hierarquia e à divisão do trabalho (Mingardi, 2007) ${ }^{12}$-, os adolescentes passaram a se organizar e construir uma nova ordem pautada na consolidação de uma estrutura mais rígida entre os internos. Foi nesta época que passaram a ser comum no interior de mui- 
tas Unidades códigos antes inexistentes; se antes já havia a figura do líder, agora ele passa a ser o voz, é aquele que passa o proceder para os demais (é o grande representante dos internos); entre ele e a população surgem novos atores que passam a ocupar esta posição "intermediária”, como é o caso dos faxinas - que são aqueles responsáveis pelo funcionamento das diferentes atividades no interior da casa (são responsáveis por organizar a limpeza, servir o almoço e ficar de campana ${ }^{13}$ ) -, e dos disciplinas, cuja função consiste em intermediar relaçóes de conflito entre os adolescentes (são eles também que controlam e disciplinam a presença dos adolescentes nas atividades pedagógicas, nos cursos e na escola formal) $)^{14}$.

\section{Práticas hierárquicas no interior $\mathrm{e}$ entre as Unidades}

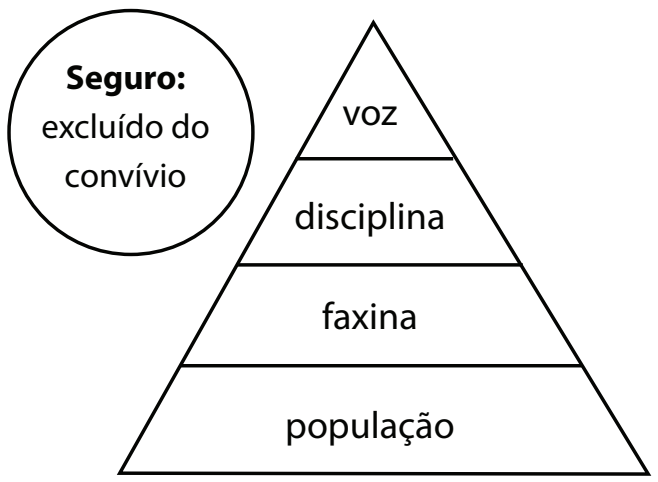

Embora o ano de 2006 tenha assistido a uma diminuição no número de rebeliōes (treze contra as trinta e quatro do ano anterior) e de fugas (cento e doze contra as mil duzentos e noventa quatro de 2005) (Penteado, 2006), este período marca, por um lado, a maior consolidação da estrutura do PCC no interior de muitas Unidades e, por outro lado, a ação dos membros da SAP no interior dos grandes complexos da Fundação.
Esta situação, em grande parte, justifica a diminuição de rebelióes e fugas, em especial com a presença dos membros da SAP, que passaram a vigiar a parte externa das Unidades e a coibir as tentativas de fuga. Soma-se o fato de que os membros da SAP, em alguns casos, passaram a negociar diretamente com as lideranças dos internos estratégias para que as casas andem sem que houvesse sucessivas rebelióes. A opção de colocá-los em negociação direta com os adolescentes decorre do fato de estes profissionais possuírem maior experiência em lidar com situaçôes do "cotidiano prisional". Do ponto de vista dos internos, a diminuição das rebelióes é consequência do comando do PCC no interior das Unidades, como disse um adolescente - ao interpelá-lo sobre o motivo da diminuição das rebeliôes: "se virar a casa por qualquer motivo, a gente leva um puxão de orelha do 'Partido'. Tem que pedir permissão antes”.

Neste contexto, tomando como universo de análise as cinco Unidades presentes no interior do Complexo Raposo Tavares, o presente artigo reter-se-á agora na análise de como cada casa constrói o seu próprio proceder, isto é, como cada Unidade constrói uma espécie de modulação de si (Soares, 2006) que regula os comportamentos e cria um padrão, um estilo:

Regular não por que fixa, congelada, condenada à repetiçáo: regular porque submetida a regras que vão se alterando, mas que são reconhecidas e, portanto, podem ser reiteradas ou reproduzidas, orientam a ação (Soares, 2006, p. 125).

Contudo, este proceder - enquanto padrão de comportamento que orienta as ações no interior das casas -, será pensado dentro da perspectiva da formação de um sistema hierárquico nas Unidades e entre as diferentes casas do Complexo. Sistema este que, como será visto, passa a produzir uma escala concebida a partir do perfil com que cada casa passa a ser rotula- 
da, tanto pelos adolescentes como pelos profissionais que trabalham na Fundação.

O proceder da Unidade e a forma como ela é encarada pelos demais adolescentes privados de liberdade é um elemento importante no que diz respeito ao cumprimento da medida socioeducativa. Isto porque a Unidade em que o adolescente fica internado passa a marcar a sua caminhadatermo utilizado pelos adolescentes para designar o período de internamento até atingir a liberdade - no interior da Fundação. Ou seja, o perfil carregado pela Unidade passa a marcar a conduta do interno no sentido de orientar sua açáo de acordo com o proceder adotado pelo local onde se encontra internado e, caso seja transferido, ele carrega consigo este perfil.

No entanto, para melhor compreender a relação entre as noçóes de caminhada e proceder, tornar-se-á necessário, no primeiro momento, acompanhar o processo de internação do adolescente na Fundação e, a partir daí, como a violência se faz presente enquanto código normativo de conduta. Será neste contexto, portanto, que as micropolíticas das forças molares (Estado e o Crime) se fazem presentes no cotidiano das Unidades, enquanto possíveis obstáculos para o cumprimento da medida socioeducativa.

Segundo o artigo 106 do ECA, o adolescente será privado de liberdade somente se for pego em flagrante de ato infracional, ou por ordem escrita e fundamentada por uma autoridade judiciária competente. No primeiro momento, ele é encaminhado para Unidade de Atendimento Inicial (UAI), onde é apresentado ao Ministério Público para audiência com o Promotor de Justiça. Ao receber a aplicação da medida socioeducativa, o adolescente, segundo o artigo 108 do ECA, é encaminhado para a Unidade de Internação Provisória (UIP).

A UIP representa uma espécie de "ritual de passagem”, para aqueles que estão debutando na Fundação, marca o início de sua caminhada.
Como diz seu nome, estas Unidades Provisórias são espaços onde os adolescentes passam por um curto período de tempo - no máximo 45 dias - até o Juiz decidir por qual medida socioeducativa o adolescente deverá ser encaminhado (prestação de serviço à comunidade, liberdade assistida, regime de semiliberdade ou internação) e, em caso de internação, para qual Unidade ele será enviado. As UIPs são conhecidas por serem casas dominadas rigidamente pelos funcionários, onde os internos são obrigados a andar com a cabeça baixa e a mão para trás, além de sempre ter que pedir 'licença senhor' ao passar por um funcionário, como mostra o relato de Cleonder Evangelista ao passar por uma dessas Unidades:

Mandaram que eu retornasse à sala de televisão [...]. No caminho passei por um funcionário. Ele tinha um pedaço de madeira, grosso como um caibro, na mão direita. A próxima coisa que senti foi o golpe na coxa esquerda, quase no quadril. Não aguentei de dor e caí. Apareceu um segundo funcionário, que me deu um chute no meio do estômago, enquanto eu ainda estava no chão. Só quando me sentei em um canto, espremido entre os outros, é que pensei em uma razão para a surra que havia levado: eu me esquecera de dizer 'licença senhor', ao passar pelo funcionário (Evangelista, 2004, p. 23-24).

Para o adolescente infrator este momento marca em seu próprio corpo a passagem do mundão para a realidade do internamento. Por mundão entende-se a categoria nativa desenvolvida pelos internos, que indica o mundo de fora em contraposição aos limites físicos das Unidades. Além de opor o dentro e o fora, a categoria de mundão também define papéis que vão desde objetos (como, por exemplo, as roupas), passando por pessoas (ser ou não funcionário da Fundação), até a classificação para as próprias histórias de vida dos internos (se 
ocorreram durante o período de internação ou não) (Miraglia, 2002, p. 114).

Será na UIP, portanto, que o adolescente passa a sofrer um estriamento a um corpo homogêneo produzido pela Fundação - ele passa a existir, a princípio, como um ser genérico; ele é o interno, o menor, o jovem em conflito com a lei. Este é um dos motivos que faz com que a UIP seja considerada uma casa veneno, pois como uma espécie de "ritual de passagem" - a violência é o meio de transformar o meliante, $o$ adolescente infrator, em interno. Ao mesmo tempo em que sofre este processo de uniformização, o adolescente também passa a ser padronizado e classificado pelo crime cometido; assim, de acordo com a gravidade do delito, ele será encaminhado a uma determinada Unidade que possua seu "perfil criminoso".

No entanto, logo que chega à Unidade de Internação, o adolescente passa a definir seu papel no interior da casa. Para isso, dentro deste universo a princípio homogêneo, o interno passa a construir para si uma espécie de capital simbólico, dado pela consonância de diferentes fatores, que além de o distinguir dos outros adolescentes, também marcará a sua $c a-$ minhada. Pude perceber no cotidiano das Unidades que, entre os acontecimentos que irão influenciar sua caminhada - como elementos de singularidade frente à condição genérica do interno (Miraglia, 2002, p. 120) - destacamse: o crime cometido que o levou à internação, a sua quebrada ${ }^{15}$ de origem (bairro), o conceito que ele possui dentro do universo criminal, o tempo que está internado, a sua caminhada na Fundação, isto é, as Unidades pelas quais já passou e seu carisma nas relações cotidianas dentro do pátio. Estas variantes (crime, quebra$d a$, conceito, tempo, caminhada e carisma) irão determinar também a posição que cada adolescente irá cumprir na hierarquia das casas, isto é, se ele será voz, disciplina, faxina, população, ou mesmo se ele será excluído do convívio com os demais internos, passe a ser seguro.

O seguro, do ponto de vista dos internos, é constituído por adolescentes que não honraram com o crime, isto é, são aqueles que realizaram algum tipo de prática, dentro ou fora das Unidades, que vai contra os padróes morais estipulados pelos internos. As principais práticas condenadas por eles são: o estupro, o desrespeito à visita alheia (olhar para a família de outro interno, andar sem camiseta enquanto houver visita no pátio ou colocar a mão nas áreas genitais), além do não cumprimento das regras de convívio estipuladas pelos adolescentes que ocupam os cargos de liderança, ou seja, promover a desuniāo entre os internos.

A existência do seguro evidencia "uma hierarquia entre os infratores, uma 'banca' em cima, e os seguros em baixo" (Farias; Narciso, 2004, p. 101). Logo, dentro da estrutura de poder construída pelos adolescentes, o seguro é considerado o nível mais baixo desta escala hierárquica, configura-se como uma espécie de “cadeia da cadeia”, já que são expulsos do convívio social, tanto do mundão, como do pátio.

Existem, basicamente, três destinos para o adolescente que passa a ser tratado pelos outros internos como pilantra (outra forma como o seguro é chamado). No primeiro caso, ele permanece no pátio, mas os outros internos o destacam do convívio, ou seja, ele é isolado de modo que não possa se comunicar com ninguém. Esta situação pode colocar em risco a vida do adolescente, pois ele se torna a vítima preferencial dos outros internos:

[...] toda rebelião é uma oportunidade para acertar as contas entre indivíduos ou grupos, mas especialmente os que estão no seguro, e que formam uma subclasse dentro da comunidade dos internos" (Farias; Narciso, 2006, p. 73).

Estavam mais ou menos uns trinta menores debaixo dos chuveiros, e desses trinta, uns dez 
bateram no Zequias - no que chamam de trembala. Zequias começou a gritar. Isto chamou a atenção dos funcionários, que correram para o banheiro e o encontraram com o rosto sangrando e o levaram para enfermaria. Foi constatado que ele havia perdido dois dentes e tivera sete dedos quebrados (Evangelista, 2004, p. 117).

Esta situação narrada acima evidência a ideia de "performance enquanto prática de justiçamento" (Soares, 2006), na medida em que, na lógica dos internos - calcada em uma cultura carcerária -, o julgamento já é dado de antemão e a pena tem como objetivo reiterar e reforçar os laços sociais de lealdade (idem, 2006, p. 132). Neste contexto, não há culpa no ato de agressão, pois esta ação visa cumprir um papel restaurador, de reparar a ordem e produzir lealdades. Até entre os funcionários, em alguns casos, parece haver uma certa conivência a estas práticas performáticas: “[...] já de imediato o funcionário pediu para reunir todo o pessoal, mas ninguém se apresentou. O funcionário disse: Ah, é estuprador mesmo" (Evangelista, 2004, p. 117).

Nos outros dois casos, o seguro é retirado do convívio com os demais adolescentes, podendo ocupar um espaço isolado dentro da própria Unidade, como forma de resguardá-lo contra a retaliação dos outros internos, mas, por outro lado, acaba sendo alijado de atividades socioeducativas coletivas como, por exemplo, a escola formal e os cursos profissionalizantes. O seguro pode também ser enviado para uma Unidade destinada só para esse grupo. No caso do Complexo Raposo Tavares, eles ocupavam uma espécie de "mini-unidade" conhecida como anexo. Porém, isto não garante o fim das animosidades, pois "não há um sentido de classe entre os seguros, sendo que uns internos são rejeitados até pelos outros "pilantras" (Farias; Narciso, 2006, p. 104), ou seja, nestas casas surge o seguro do seguro.
É importante ressaltar que os adolescentes que se encontram na situação de seguro também sofrem uma discriminação de muitos profissionais que trabalham para o cumprimento da medida socioeducativa, seja por uma repulsa pelo crime cometido (principalmente o estupro), seja por sua agressividade frente aos funcionários durante as rebelióes:

O virar da casa é uma oportunidade que o seguro pode usar para calar aqueles que sabem que ele é 'pilantra' - esses são os internos que abordam os monitores com intençáo de matar, seja para calá-los, seja para parecer 'bandido' e não 'pilantra', diante do restante da população de internos (Farias; Narciso, 2006, p. 105-106).

Se a posição do seguro acena para existência de formas hierárquicas entre os internos, dada por um proceder baseado na idéia de honrar ao crime, esta mesma lógica pode ser percebida na relação que existe entre as Unidades, pois:

[...] é possível dizer que, de certa forma, cada Unidade tem uma vida autônoma, um cotidiano independente, regras próprias que se misturam às regras institucionais, na fala nativa, cada Unidade tem o seu próprio proceder (Miraglia, 2002, p. 91).

Neste sentido, o desafio do texto agora é desvendar como, dentro do Complexo Raposo Tavares, cada Unidade constrói o seu próprio proceder, por meio de negociaçóes e conflitos entre as regras institucionais e aquelas almejadas pelos adolescentes, e como, ao construir para si um padrão, uma estética, cada casa passa a ocupar uma posição dentro da escala hierárquica determinada pelo conceito que cada Unidade tem em honrar com o crime. Logo, a Unidade que se encontra um patamar "acima" do seguro é a UI-22.

A UI-22 é considerada uma casa diferenciada dentro do Complexo, a começar pelo 
perfil de seus internos: basicamente toda sua população é formada por adolescentes que cometeram crimes considerados leves e que estão passando pela primeira vez por um processo de internação. Parte de sua população é constituída por pedrinhas - forma como os jovens de baixa estatura e com pouca idade (geralmente entre 14 e 15 anos) são conhecidos no interior da Fundação. Ela também é conhecida por ser uma casa que anda, ou seja, além de os adolescentes permanecerem pouco tempo internados - dando um dinamismo a sua população -, ali também existe um trabalho institucional mais estruturado.

Quando se diz trabalho institucional, entende-se tanto a ação mais próxima da área técnico-pedagógica (a presença da escola, dos cursos profissionalizantes e culturais, atendimento psicológico, assistência social, atividades junto às famílias), como uma maior presença dos funcionários sobre a rotina da casa. Nas Unidades consideradas mais estruturadas, o adolescente cumpre o seu papel de interno, enquanto o funcionário age como organizador da vida com privação de liberdade (Farias; Narciso, 2006). Isto faz com que nesta Unidade os gestos sejam mais vigiados e o tempo "mais administrado" por parte da Fundação, de maneira que as açóes institucionais preenchem grande parte do tempo dos adolescentes.

Contudo, é importante lembrar que a forma de dominação dos funcionários não ocorre como nas UIPs, ou em alguns casos como nas Unidades que recebem uma população reincidente, casas estas em que se busca ter o controle através do rígido, e por vezes violento, regime de tranca e de cabeça baixa e mão para trás. $\mathrm{Na}$ UI-22, ao contrário, o controle se dá de uma forma que pode ser considerada "mais branda", isto é, a direção estipula as regras e os internos acatam estas normas, sob a contrapartida de que a casa permaneça andando. Em outras palavras, em troca do "bom comportamento", os adolescentes ganham sua liberdade com maior rapidez; dificilmente se passa mais de um ano ali (isto se deve também ao fato de estes internos terem cometido crimes considerados "leves", tal como porte de arma e assalto sem causar danos à vítima). Para muitos profissionais que ali trabalham, esta situação só é possível devido à baixa periculosidade dos internos ou, como dizem os adolescentes de outras Unidades, "na UI-22 os menores não sabem ainda bem qual é o proceder do crime".

Foi dentro desta realidade que durante os períodos de maiores turbulências no interior da Fundação a UI-22 foi a única das Unidades do Complexo Raposo Tavares que passou ilesa dos ciclos de rebelióes que tomaram conta das outras casas. Esta postura fez com que, por um lado, o trabalho da instituiçáo, no que tange ao cumprimento da medida socioeducativa, pudesse se estruturar e ter maior continuidade; mas por outro lado, do ponto de vista do proceder dos internos de outras Unidades, esta postura de não ir para o arrebento e levantar a casa - ou seja, de tirar a Unidade da mão dos funcionários - fez com que a UI-22 se tornasse mal vista pelos outros internos do Complexo. Para eles, a UI-22 não representa, isto é, não segue o "padrão do crime"16.

A repulsa aos internos da UI-22 pelos demais adolescentes do Complexo varia de acordo com a Unidade, visto que na UI-28, que abriga alguns ex-internos da UI-22, a justificativa para a postura dos adolescentes da UI-22 é de que eles não sabem bem ainda qual é o proceder $d a$ cadeia $^{17}$. Já para os internos de Unidades como a UI-37 e a UI-38, não existe nenhum tipo de atenuante para a postura dos adolescentes da UI-22; ao não correr com o crime, são considerados pilantras, e azar daquele que por ventura seja transferido para uma dessas casas.

Todavia, na UI-22 parece haver um espaço para o "direito à infância", permitindo inclusive uma maior aproximação entre funcionários 
e internos ${ }^{18}$, fato inexistente em outras Unidades, visto que o proceder que permeia as relações nestas outras casas não permite a existência de qualquer comportamento considerado "infantil" ou "afetivo" com algum funcionário. Nas outras casas, como uma estratégia de sobrevivência - frente a um ambiente onde a violência é o código normativo de comportamento -, o adolescente deve ser sujeito homem, ou seja, deve adotar uma postura em que "o orgulho de ser homem não se origina na gentileza e outras disposiçôes civilizadas, mas na capacidade e disposição de destruir o adversário" (Zaluar, 2007, p. 46).

As Unidades 27 e 28, por sua vez, encontram-se em uma posição intermediária da escala hierárquica, isto porque, embora representem, isto é, adotem a postura de correr com o crime, também permitem uma maior negociação com as regras institucionais. A princípio, estas casas eram destinadas ao internamento de adolescentes com o perfil primário médio/primário grave, mas pôde ser observada a existência também de adolescentes reincidentes. Nestas Unidades, ao contrário da UI-22, quem dita as regras já não são mais os funcionários; isto faz com que a organização da vida em privação de liberdade passe para o controle dos internos: são eles que estipulam as regras de convivência no interior do pátio. Normas que, em especial a partir de 2005 , passaram a seguir a disciplina imposta pelo "Partido" 19

Esta situação só se inverte, geralmente, após as rebeliôes, quando os funcionários passam a dominar a casa se valendo do regime de tranca. Nestes momentos as açóes visando ao cumprimento da medida socioeducativa são paralisadas, fazendo com que o trabalho pedagógico seja preterido pela atividade de contenção. Em alguns casos, o uso da violência física passa a ser o recurso pelo qual parte dos funcionários passa a organizar a vida do adolescente privado de liberdade.
No entanto, pode ser observado que esta relação não consegue se manter por muito tempo, pois os adolescentes não aceitam permanecer em uma estrutura de coerçáo - no que eles denominam de estar no ritmo de UIP. Muitas vezes, a busca pela restauração do proceder dos internos recebe a solidariedade de adolescentes de casas vizinhas, que passam a pressionar as autoridades do Complexo para que haja um fim da opressão (é a forma como os internos se referem à atitude rígida dos funcionários quando estes passam a controlar as açôes dentro das Unidades).

Esta disputa pelo poder no interior da Unidade, somada ao tipo de crime (mais grave) cometido por estes adolescentes e a existência de internos reincidentes, faz com que estas casas náo andem. Nestes locais, é mais comum haver uma renovação no quadro da população devido à transferência entre as Unidades (ou para Centros de Detenção Provisórios) do que por desinternação. As transferências, por sua vez, estipuladas pela Fundação, reiteram uma escala hierárquica do crime, pois, geralmente, a UI28 costuma receber adolescentes que criaram algum tipo de problema na UI-22 e são transferidos para lá; já os internos considerados "problemáticos" da UI-28 costumam ir para UI-38, enquanto na UI-27 os adolescentes costumam parar na UI-37. Em alguns casos, como uma "moeda de troca", adolescentes da UI-38 vão para a UI-28 e da UI-37 para a UI-27. Contudo, é muito raro que algum adolescente destas casas vá parar na UI-22, isto porque ele poderá ser um agente de desestruturação da Unidade. Por outro lado, é difícil que um interno da UI22 seja transferido diretamente para a UI-37, já que entre estes dois universos existem gradaçóes, que quando ignoradas póem em risco a integridade física do adolescente.

A UI-37 e a UI-38 - que até 2006 estavam localizadas uma ao lado da outra em uma espécie de "minicomplexo" considerado de seguran- 
ça máxima - é formada por uma população de reincidentes graves (UI-38) e gravíssimos (UI37). Assim como acontece nas Unidades 27 e 28 , nestas casas os adolescentes exercem grande poder, fazendo com que qualquer ação institucional necessite passar anteriormente por uma negociação junto aos internos. Todavia, tanto na UI-37 como na UI-38, por receberem um público considerado de maior periculosidade, as relaçóes - tanto entre os internos, como a que estabelecem com os diferentes profissionais que ali atuam - obedecem a um maior distanciamento e a um controle mais rigoroso por parte das lideranças.

Nestas casas, os postos hierárquicos construídos pelos internos tornam-se mais nítidos. Assim, qualquer conversa ou eventual saída de algum adolescente da Unidade é intermediada por um disciplina, que busca vigiar ao máximo os gestos tanto dos internos como dos funcionários, que podem apenas circular e permanecer em locais anteriormente estipulados pelos adolescentes. Cabe aos disciplinas também evitar que funcionários, sejam eles de segurança, da pedagogia ou mesmo professores, fiquem a sós com algum adolescente: para isso, uma determinação passada pela liderança aos profissionais que ali trabalham é de que náo fiquem chicletando, ou seja, não busquem conversar com qualquer adolescente.

A postura mais rígida nestas Unidades se configura como uma estratégia de controle por parte da liderança dos internos para que não vaze nenhum tipo de informação sigilosa de dentro do pátio (para que não haja caguetagem), tal como planos de fuga e esquemas de tráfico de drogas. A atitude de rigidez possibilita ainda que determinadas firmas ${ }^{20}$ sem poder na casa não consigam se articular para tomar o controle da Unidade.

$\mathrm{Na}$ realidade, estas Unidades se caracterizam como uma espécie de "depósito de corpos indesejáveis”, já que são o destino final de muitos adolescentes que causam distúrbios em outras casas. Esta situação faz com que as Unidades 37 e 38 ocupem o topo da escala hierárquica concebida pelos internos e, de certo modo, incentivada pela Fundação.

Um indicativo que evidencia o controle da casa pelos internos é a presença de objetos do mundão no pátio. Assim, o grau de controle da Unidade por parte dos adolescentes pode ser medida pela quantidade destes objetos em seu poder, que pode variar desde roupas, tênis e relógios até casos mais graves, como a posse de celulares, drogas ilícitas e armas de fogo. A aquisição destes bens é um indicativo que mostra um alto grau de permeabilidade frente às restriçôes impostas pelo regimento Fundação; como consequência, as regras institucionais visando ao cumprimento da medida socioeducativa acabam não conseguindo se estruturar, assim como torna clara a existência de um eficiente canal ilegal de entrada destes produtos na Unidade.

A existência destes objetos do mundão indica ainda para relaçáo de status e poder existente entre os adolescentes, isto porque a posse destes objetos não acontece de modo aleatório, mas obedece a hierarquia construída pelos adolescentes. Assim, por exemplo, aqueles que portam roupas que não são os uniformes da Fundação geralmente não são os adolescentes da população, mas sim integrantes da firma que se encontra no poder. Inclusive, quando há poucos objetos de fora da Fundação, como apenas um boné ou uma camiseta, estas indumentárias são compartilhadas e circulam entre os membros pertencentes ao quadro das lideranças, como forma de afirmar o status e o poder de determinados internos.

Embora esta situação venha ocorrer nas diferentes Unidades onde a casa encontra-se sobre forte poder dos internos, o grau de dominaçáo e do conceito com o crime é diferenciado de acordo com o perfil que cada casa possui. 
I 22 | Maurício Bacic Olic

Assim, a escala hierárquica no interior do Complexo Raposo Tavares obedece à seguinte "gradação":

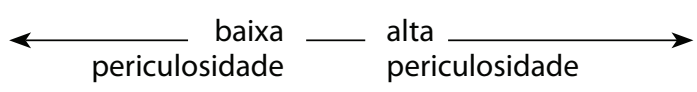

\section{\begin{tabular}{|l|l|l|l|l|}
\hline UI-22 & UI-28 & UI-27 & UI-38 & UI-37 \\
\hline
\end{tabular}}

Logo, em virtude desta variação de grau, determinada pelo perfil que cada casa possui, a UI-37 passou a exercer o papel de Unidade piloto do Complexo Raposo Tavares, isto é, ela passou a concentrar o poder de decisão do Complexo. Assim, por exemplo, os internos das outras casas só poderiam se rebelar com a devida autorização da Unidade "central". Isto fez com que a UI-37 acabasse por ser considerada por adolescentes e funcionários como o local da diretoria do crime, onde aqueles que por lá passam têm a responsabilidade de honrar a cadeia em que estáo. O prestígio de se ter passado pela UI-37 é verificado também quando um interno desta Unidade é transferido, uma vez que ele passa a carregar consigo o "status 37 " para a sua nova Unidade. Este prestígio faz com que ele, desde o princípio, seja considerado pelos demais internos, sendo que, muitas vezes, logo que chega, já passa a assumir um papel proeminente na hierarquia da casa.

Portanto, a UI-37 acabou por construir ao largo da medida socioeducativa - um imaginário para si que mistura, por um lado, uma espécie de admiração por se tratar de adolescentes que atingiram um "status no crime" por meio da imposição de suas próprias regras - balizadas por uma espécie de cultura carcerária frente à situação de privação de liberdade. Mas, por outro lado, sua imagem como lugar em que a casa náo anda, ou seja, onde a liberdade demora a sair, cria um sentimento de esquecimento e alimenta o ciclo de violência, faz com que muitos adolescentes tenham também medo de um dia ir parar lá.

\section{Consideraçóes finais}

Para concluir, podemos dizer que a realidade vivenciada no interior das Unidades aponta para uma limitação do Estado, que através de seus aparatos jurídicos (Estatuto da Criança a dos Adolescentes) e de seu aparelho institucional (atual Fundação CASA) busca romper com a lógica da "vingança" como meio da contenção dos ciclos de violência produzidos pelo crime (Robert, 2002).

Assim, se a princípio o cumprimento da medida de socioeducativa de privação de liberdade busca ser um meio de interromper o ciclo de violência no qual os jovens encontram-se inseridos, com a ineficácia do Estado em gerir seus espaços de internação, uma nova lógica de violência - alimentada pela animosidade e um certo "desejo de vingança" entre funcionários e adolescentes - acaba por restituir um novo sistema de vingança, onde a relação jurídica (a cargo do Estado) é sucumbida pela relação pessoal de vendeta (Robert, 2002, p. 27) entre funcionários e adolescentes.

Como Paula Miraglia (2002, p. 96) aponta, esta situação coloca os funcionários em um duplo e ambíguo papel; ora são vistos como vilóes por espancarem os adolescentes, ora são tidos como heróis por trabalharem em uma instituição que não lhes oferecem condiçóes mínimas para exercerem suas respectivas funçóes. Os funcionários Paulo e Laércio - ao comentarem sobre as possíveis razóes das arbitrariedades cometidas pelos funcionários - indicam como esta relação ambígua é fruto da própria estrutura da Fundação:

Os excessos cometidos contra os internos têm raízes diversas: haveria na FEBEM homens com um pendor para o sadismo ou para o descontrole, que poderiam ser eliminados em uma triagem mais eficaz; existem ainda aqueles que, após passarem por traumas violentos em atenta- 
dos ou rebeliôes, são forçados a trabalhar mesmo estando abalados psicologicamente - obrigados a lidar diariamente com os seus agressores; e há ainda situaçōes, provocadas por diretores e administradores incompetentes, de falta de liderança e de ordens conflitantes que, associadas, por exemplo, à superlotação ou a condiçóes deficientes de contenção dos menores, levariam aos excessos (Farias; Narciso, 2006, p. 14).

Esta situação acaba fazendo com que a violência permaneça um elemento estrutural que atravessa a vida social da Fundação, manifestação esta que possui uma forma cultural detentora de um padrão, disciplina, estilo e linguagem próprios e que, por fim, acaba expondo o adolescente a uma situação onde:

O que está no fundo do quadro, como referência, é a construção do futuro, a construção de si; e são duas formas de associação [...] uma que se encontra na lógica de nossa justiça criminal e outra que se afirma, tacitamente, na prática de “justiçamento" (Soares, 2006, p. 124).

Portanto, o adolescente que se encontra privado de liberdade, ao buscar criar um novo campo de possibilidades de mudança no período de cumprimento da medida socioeducativa, acaba por enfrentar um duplo obstáculo - constituído por forças molares - ao almejar uma reinvenção de si: por um lado se vê frente ao Estado com suas limitaçóes em gerir as Unidades; por outro lado o interno encontra-se sujeito à lógica do justiçamento, "que se fundamenta, simplesmente, na necessidade prospectiva de produzir a lealdade, de reiterar uma certa ordem" (Soares, 2006, p. 133-134). Ordem esta perpetrada pelo crime, e tendo na violência o instrumento performático de lealdade:

Os seus algozes, garotos como ele, haviam enfiado uma 'espada' em um dos seus ouvidos, arras- tado o corpo até o ponto em que foi pendurado e fogo ateado nos seus restos. Antes disso, seu peito fora aberto e o coração arrancado e exibido como um troféu por seus assassinos [...] ele era um pé-de-pato, um matador de aluguel, matador de bandidos (Farias; Narciso, 2006, p.85).

\section{Who rules the house? Hierarchy and po- wer relations in Detention Units for young offenders}

abstract The purpose of this article is to analyze the dispute within different Detention Units of the Center for Adolescent Social Service (former FEBEM). Based on daily empirical observation conducted in the Units - as a teacher at its formal school in the Raposo Tavares Complex in the city of São Paulo from 2004 to 2006 -, it assesses the dynamics and mechanisms of power in the routine of adolescents and professionals working to fulfill the social and the educational measure.

keywords Social Educative System. Internal Units. Hierarchy.

\section{Notas}

1 No período que o artigo busca investigar (2004 06), existiam no estado de São Paulo os seguintes complexos, todos localizados na região metropolitana do estado: Brás, Tatuapé, Vila Maria, Raposo Tavares e Franco da Rocha.

2 Administrativamente, também fazem parte do Complexo Raposo Tavares as Unidades de Pirituba e Vila Leopoldina (inaugurada no segundo semestre de 2006), localizadas nos bairros que constam em seus nomes, ambos na zona oeste da capital. Por não terem uma contiguidade espacial com as outras Unidades do Complexo, estas duas casas não foram contempladas no universo de pesquisa.

3 A área pedagógica é constituída por profissionais com formaçōes diversas no nível superior, cujas atividades são voltadas ao acompanhamento das atividades pedagógicas (escola formal, cursos profissionalizantes 
e culturais e a capelania) no interior da Unidade. A área de segurança, por sua vez, é constituída, majoritariamente, por homens que se dividem em turnos de doze horas, cujas atribuiçôes envolvem a organização do dia a dia dos adolescentes e o acompanhamento deles em atividades tanto no interior como no exterior da Unidade. O grupo de funcionários de pátio se divide entre monitores e coordenadores. Esta é a equipe que passa a maior parte do tempo com os adolescentes. Já a área técnica é formada, majoritariamente, por mulheres com formação nas áreas de psicologia e assistência social, em que cabe a elas fazer o atendimento psicológico e social junto aos adolescentes. São as técnicas também que redigem os relatórios semestrais ao juiz indicando os progressos do adolescente.

4 A ideia de afetividade aqui utilizada remete não a um sentimento, mas sim à capacidade de afetar e de ser afetado pelo outro (cf. Favret-Saada apud Goldman, 2006).

5 Neste período, uma cena comum nas Unidades era o grande número de funcionários que permaneciam sua jornada de trabalho do lado de fora do pátio (seja por interdiçáo dos adolescentes, seja por veto médico), enquanto no interior - no pátio - verificava-se a quase inexistência de funcionários.

6 Embora os adolescentes demonstrem um profundo respeito pela figura do professor, isto náo impede que em alguns casos eles sejam mantidos como reféns durante as rebelióes, como pude acompanhar em rebelióes que ocorreram em 2004 (UI-28), 2005 (UI-38) e 2006 (UI-27).

7 É como são chamados os pertences trazidos pelos familiares nos dias de visita.

8 Equipe da área de segurança da Fundação que trabalha no interior dos Complexos, mas fora das Unidades. Realizam o trabalho de contenção em caso de tentativas de fuga e rebelião. São eles também que, muitas vezes, efetuam a revista no quarto dos adolescentes. O nome choquinho é uma alusão ao batalhão do choque da PM, isto porque o uniforme e equipamento utilizados por ambos são parecidos.

9 Em muitos casos, após as rebeliōes as lideranças são transferidas da Unidade como forma de desarticular a organizaçáo dos internos, de modo a facilitar o domínio dos funcionários. Porém, rapidamente, novas lideranças emergem, contribuindo pra a perpetuação do ciclo.

10 Sobre a ação da Secretaria de Administração Penitenciária na FEBEM, conferir Penteado (2006).
11 A ênfase da Fundaçấo para medidas de contençấo em prol da medida socioeducativa ficou explícita no Complexo Raposo Tavares, com a desativaçáo do prédio da secretaria escolar, para em seu lugar abrigar o alojamento dos integrantes do Grupo de Intervençáo Rápida.

12 Segundo Mingardi (2007) são cinco as características que definem o crime organizado e o diferenciam do crime comum: a hierarquia, a previsão dos lucros, a divisão do trabalho, o planejamento empresarial e, por fim, a simbiose com o Estado.

13 Campana é a função de vigia na qual um adolescente é designado para ficar próximo à entrada da Unidade - na gaiola - acompanhando toda movimentaçáo que acontece, de modo a passar as informaçóes a seu superior hierárquico.

14 Neste mesmo sentido a reportagem Gilmar Penteado (2005) aponta: "Nos últimos meses, termos como voz, disciplina e faxina passaram a se popularizar entre os internos da FEBEM. Mas, ao contrário de meras expressóes criadas pelos adolescentes, esses termos fazem parte de um sistema hierárquico, semelhante ao adotado em presídios, que se fortalece cada dia na fundação".

15 A categoria nativa de quebrada é uma forma "positivada" pela qual novos atores residentes da periferia vêm ressignificando este espaço, em que, ao invés de remeter à idéia de precariedade, constrói uma concepção positiva de pertencimento.

16 No primeiro semestre de 2005, cerca de cem internos da UI-27 escaparam da Unidade no intuito de invadir a UI-22 e tomar a casa da mão dos funcionários. A tentativa acabou falhando e os adolescentes se dirigiram à UI-28, onde uma violenta rebeliáo estourou, só controlada com a presença da Tropa de Choque da Policia Militar.

17 Além de permitirem aos funcionários terem o domínio sobre a Unidade, os adolescentes da UI-22 são mal vistos também por terem atitudes consideradas de pilantra, como, por exemplo, a existência de briga entre os internos dentro das salas de aula, ação esta inexistente e repudiada como patifaria pelos adolescentes das outras casas.

18 Sobre esta relação mais próxima entre monitor e adolescente, conferir o capítulo "Questôes e esperanças" (Farias \& Narciso, 2006).

19 Entre as açōes que puderam identificar a existência da organização do PCC nestas Unidades, destacam-se a existência das "rezas" antes das refeiçóes, além dos 
salves - também conhecidos como cola cadeia - que é o código para que todos internos se reúnam para as lideranças passarem alguma informação. Também neste período tornou-se mais comum a presença de símbolos ligados ao "Partido", tal como, o "PJL" (paz, justiça e liberdade), o símbolo chinês do ying e yang e os números 1533 (referente à posição das letras P-C-C no alfabeto).

As firmas são agrupamentos formados por algum tipo de afinidade como, por exemplo, parentesco, residir em quebradas próximas ou já terem ficado internados juntos anteriormente. Este tipo de organizaçấo acontece praticamente em todas unidades, são conhecidas também como banca.

\section{Referências bibliográficas}

ADORNO, Sérgio; SALLA, Fernando. Criminalidade organizada nas prisões e os ataques do PCC. Estudos Avançados, n. 61, p. 07 - 30, 2007.

DELEUZE, Gilles; GUATTARI, Felix. Mil Platôs: capitalismo e esquizofrenia. São Paulo: Editora 34, 1997 (vol. V.).

ELIAS, Roberto João. Comentários ao estatuto da criança e do adolescente. São Paulo: Saraiva, 2002.

EVANGELISTA, Cleonder. Luz no fim do túnel. São Paulo: Arte \& Ciência, 2004.

FARIAS, Paulo Sérgio; NARCISO, Laércio. Cadeia de chocolate. São Paulo: Arte \& Ciência, 2006.
GOFFMAN, Erving. Manicômios, prisóes e conventos. São Paulo: Perspectiva, 1974.

GOLDMAN, Marcio. Como funciona a democracia: uma etnografia da política. Rio de Janeiro: 7 Letras, 2006.

MINGARDI, Guaracy. O trabalho da inteligência no controle do Crime Organizado. Estudos Avançados, n. 61, p. 51 - 70, 2007.

MIRAGLIA, Paula. Rituais de violência: a FEBEM como espaço do medo em São Paulo. Dissertação (Mestrado) - Faculdade de Filosofia, Letras e Ciências Humanas, Universidade de Sáo Paulo, São Paulo, 2002.

PENTEADO, Gilmar. Internos reproduzem hierarquia de presídios. Folha de São Paulo, São Paulo, 02 mai. 2005. Caderno Cotidiano, p. C-1.

Agente de presídio na FEBEM é investigado. Folha de São Paulo, São Paulo, 02 out. 2006. Caderno Cotidiano, p. C-6.

RAMOS, Victor. Alckmin tira FEBEM da esfera da educação. Folha de São Paulo, São Paulo, 27 out. 2004. Caderno Cotidiano, p. C-4.

ROBERT, Philippe. Sociologia do crime. Petrópolis: Vozes, 2007.

SOARES, Luis Eduardo. O futuro como passado e o passado como futuro: armadilhas do pensamento cínico e política da esperança. In: ALMEIDA, M. I. \& EUGENIO, F. (orgs.) Culturas Jovens: novos mapas do afeto. Rio de Janeiro: Jorge Zahar Editor, 2006, p. $121-138$.

ZALUAR, Alba. Democratização inacabada: fracasso da segurança pública. Estudos Avançados, n. 61, p. 31 50, 2007.

autor

Maurício Bacic Olic

Mestrando em Ciências Sociais/PUC-SP

Recebido em 26/03/2009

Aceito para publicação em 06/11/2009 